Egypt. Acad. J. Biolog. Sci., 5(1): 53 - 57 (2013)

Email: egyptianacademic@yahoo.com

Received: 20 / 9 / 2013
C. Physiology \& Molecular Biology

ISSN: 2090-0767

www.eajbs.eg.net

\title{
The role of information sources in anemia knowledge in Qassim region, Saudia
} Arabia

\author{
Hisham Ali Waggiallah and Mahmoud Mohamed Elgari \\ Department of medical laboratory, Faculty of medical applied science, Taibah \\ University. P.O Box 3001, Almadenah Almonawarah, Saudia Arabia.
}

\begin{abstract}
Anemia is a global public health problem affecting both developing and developed countries with major consequences for human health as well as social and economic development. The aim of this study to assess the role of information sources in anemia awareness. This cross-sectional community-based study was conducted throughout the Qassim region which has been divided into 11 provinces were evaluated. A total of 1281Saudi citizens participated in this study. Each participant was asked to answer a total of 18 questions from a pre-piloted questionnaire. 1281 questionnaires were distributed the response rate was 95.7\%. Males represented $62.2 \%$. General knowledge of anemia was $89.5 \%$ of the study population. Satisfactory, fair, and poor awareness of anemia represented $20.5 \%, 50.5 \%$, and $29.0 \%$ respectively. Friends and relatives were constituted the major information sources while books and journals were the lowest source. We conclude that general awareness of anemia is very good, but still more efforts should be performed through information sources to boost of anemia awareness in Saudi population in Qassim area to reach satisfactory knowledge, which reflect in life style and hygiene behavior.
\end{abstract}

Keywords: information sources, anemia, awareness, knowledge.

\section{INTRODUCTION}

Information sources are the various means by which information is recorded for use by an individual or an organization. It is the means by which a person is informed about something or knowledge is availed to someone, a group of people or an organization. Information sources can be observations, people, speeches, documents, pictures, organizations. Information sources can be in print, non-print and electronic media or format. (Green et al., 2009).

Anemia is a decrease in number of red blood cells (RBCs) or less than the normal quantity of hemoglobin in the blood. However, it can include decreased oxygen-binding ability of each hemoglobin molecule due to deformity or lack in numerical development as in some other types of hemoglobin deficiency. Anemia is the most common disorder of the blood. The several kinds of anemia are produced by a variety of underlying causes. It can be classified in a variety of ways, based on the morphology of RBCs, underlying etiologic mechanisms, and discernible clinical spectra. (Fredrick and Abrahamian, 2009) Globally, the most significant contributor to the onset of anemia is iron deficiency so that IDA and anemia are often used synonymously, and the prevalence of anemia has often been used as a proxy for IDA. (WHO 2001) Among the other causes of anemia, heavy blood loss as a result of menstruation, or parasite infections such as hookworms, ascaris, and schistosomiasis can lower blood hemoglobin $(\mathrm{Hb})$ concentrations. Acute and chronic infections, including malaria, cancer, tuberculosis, and HIV can also lower blood $\mathrm{Hb}$ concentrations. The presence of other micronutrient deficiencies, including vitamins $\mathrm{A}$ and 
B12, folate, riboflavin, and copper can increase the risk of anemia. Furthermore, the impact of hemoglobinopathies on anemia prevalence needs to be considered within some populations. (Macgregor 1963; Scholl and Hediger, 1994; Bothwell and Charlton, 1981).

In order to further explore the extent of anemia awareness in Qassim community and to determine contributing factors, the study assessed the role of information sources in anemia knowledge of Saudi citizens who are living in Qassim region.

\section{MATERIALS AND METHODS}

\section{Study design and population}

This cross-sectional communitybased study was conducted throughout the Qassim region which lies approximately at the centre of the Arabian Peninsula. Qassim region has been divided into 11 provinces, Buraida, Onaiza, Al-Rass, Al-muthnab, AlBekaria, Al-Badaei, Al-Asyah, AlNabhania, Oyon Jawa, Riad Khobara, and Al-Shamasia. The study samples were collected from each province, size of which depended upon the population structure of each province as per the 2004 census (Department of Statistics, 2004). The sample size was calculated to estimate the proportion of subjects having adequate knowledge with 95\% confidence. Since this was not available for Qassim region, it was assumed that in each province, $50 \%$ of the subjects had adequate knowledge in order to get maximum sample size. A multistage random cluster technique was employed for sampling.

\section{Data collection}

The data was collected from May 2012 to February 20103. A total of 1281Saudi citizens participated in this study. Inclusion criteria for the study subjects were Saudi citizen, age $\geq 15$ years. Data was collected using prepiloted questionnaires during the visits to homes and public places that is Estarahes (party lounges), markets, and schools. The questionnaire contained a series of questions related to participant's demographic characteristics (4 questions) and awareness of Anemia including general knowledge and risk factors (14 questions), Additionally, participant's sources of information on diabetes were recorded. The questions were translated into Arabic language for better understanding of the participants. All the questions were closed-ended with the only possible answer of yes or no.

\section{Ethical consideration}

Ethical approval was obtained from the Ethics and Research Committee of Qassim University. Participation was voluntary and verbal consent was acquired from each participant.

\section{Statistical analysis}

Data were analyzed statistically using Statistical Package for Social Sciences (SPSS) version 16. Demographic variables were expressed in percentage.

\section{RESULTS}

1281 questionnaires were distributed the response rate was $95.7 \%$. Males represented $62.2 \%$. In high education males were approximately twice times educated more than female. Students represented almost half of participants. Males are more than females in all categories of education except in illiterate and primary school while in intermediate are equal. In occupation classes males were considered as twice time as females. The demographic data is shown in Table1 and illustrated in Figs.1-3. General knowledge of anemia was $89.5 \%$ of the study population. Satisfactory, fair, and poor awareness of anemia represented $20.5 \%, 50.5 \%$, and $29.0 \%$ respectively, while the mean of awareness was $44.0 \pm 22.8$. Relatives and friends was the main source of information of anemia while the books and journals was the lowest source. 
Table 1: Shows the demographic characteristic of study participants

\begin{tabular}{|c|c|c|c|c|}
\hline \multirow{2}{*}{ Variables } & \multirow{2}{*}{ Variables } & \multirow[b]{2}{*}{ Total } & \multicolumn{2}{|c|}{ Gender } \\
\hline & & & Male (728) & Female (443) \\
\hline \multirow{4}{*}{$\begin{array}{l}0 \\
0 \\
0 \\
0\end{array}$} & $15-25$ & 610 & 325 & 202 \\
\hline & $26-35$ & 250 & $\frac{52.5}{120}$ & $\frac{0.04}{94}$ \\
\hline & $36-45$ & 174 & 9.9 & 5.0 \\
\hline & $>46$ & 128 & 7.8 & 3.2 \\
\hline \multirow{5}{*}{$\begin{array}{l}\text { T) } \\
\stackrel{0}{0} \\
\stackrel{0}{0} \\
\stackrel{0}{0} \\
\text {. }\end{array}$} & Illiterate & 44 & 1.3 & 2.4 \\
\hline & Primary schools & 58 & 1.9 & 2.9 \\
\hline & Intermediate & 102 & 4.3 & 4.3 \\
\hline & Secondary & 502 & 26.6 & 15.6 \\
\hline & University and above & 484 & 27.6 & 13.1 \\
\hline \multirow{5}{*}{ 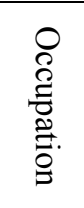 } & Students & 517 & 27.1 & 16.7 \\
\hline & Government officers & 455 & 29.6 & 8.9 \\
\hline & House wife & 143 & 0 & 12.1 \\
\hline & Labor & 22 & 1.7 & 0.2 \\
\hline & Retired & 45 & 3.5 & 0.3 \\
\hline
\end{tabular}
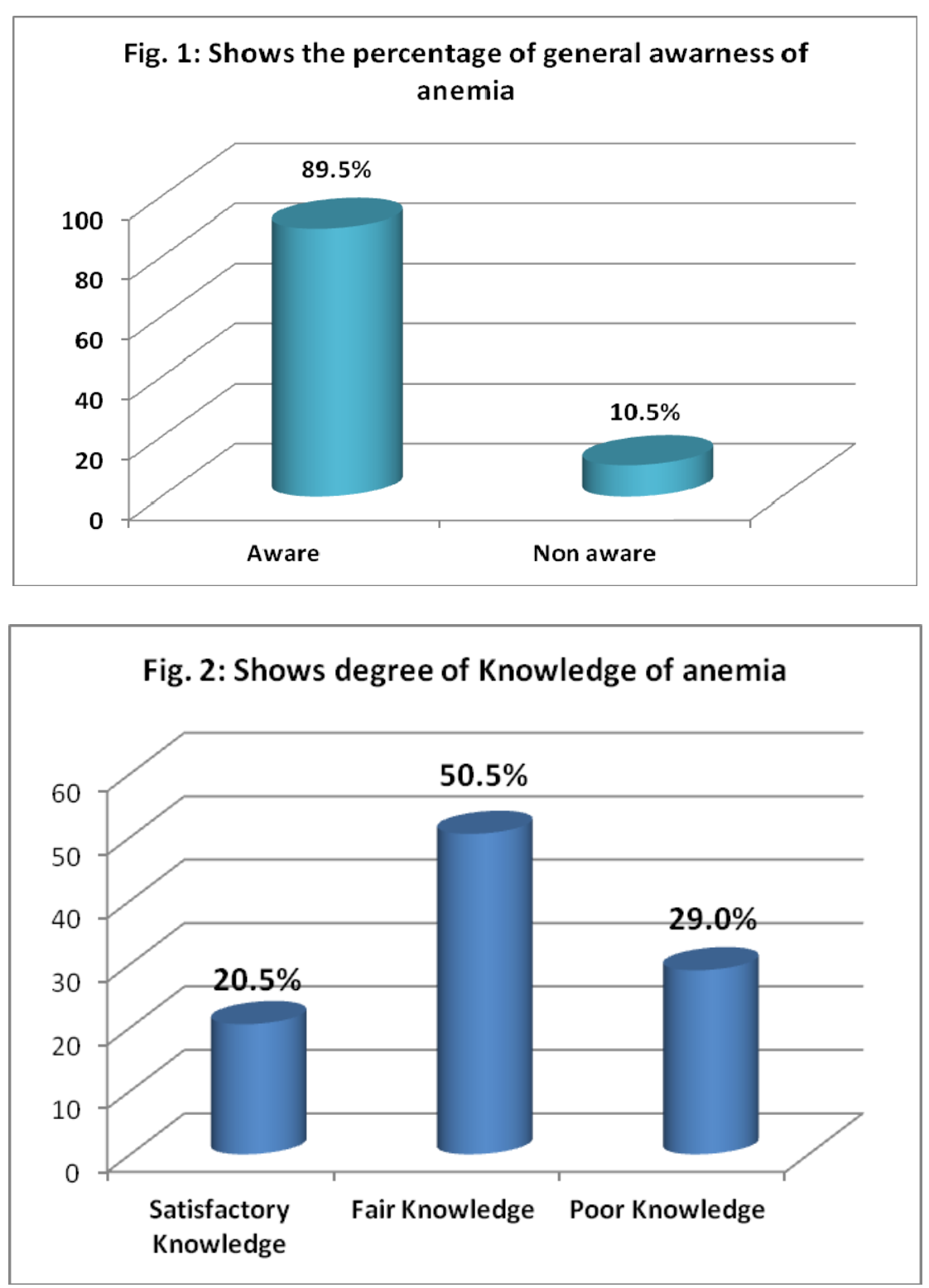


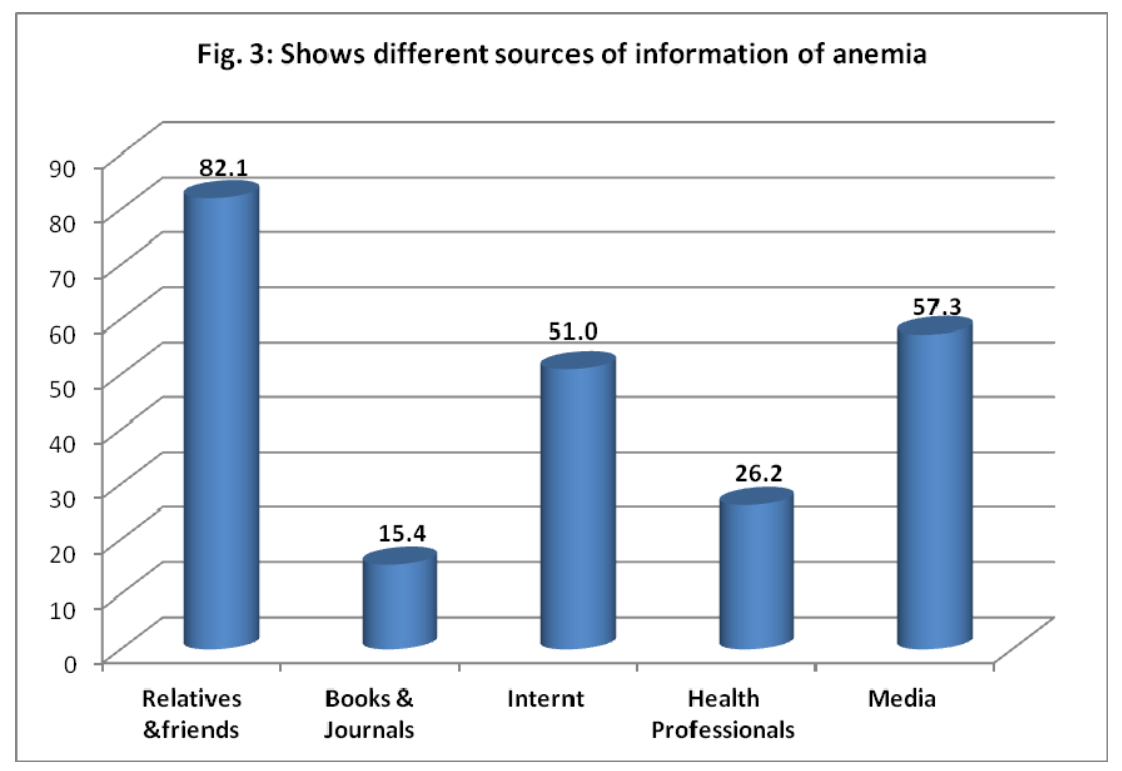

\section{DISCUSSION}

Anemia is a global public health problem affecting both developing and developed countries with major consequences for human health as well as social and economic development. It occurs at all stages of the life cycle, but is more prevalent in pregnant women and young children. (WHO, 2002)

In this study general awareness of anemia in Saudi population Qassim area was $89.5 \%$. The satisfactory knowledge of anemia is only $20.5 \%$ of the whole population which is low percentage because the sources of information are more available and the level of education is improved. Half of Saudi citizens in this study have fair awareness of anemia while one fifth of the participants with poor awareness of anemia.

In present study the major source of information is relative and friends (verbal knowledge) which was constituted $82.1 \%$ and the lowest source was book and journals $(15.4 \%)$ which mean books and journals were not source of choice due to many reasons such as increase distribution of internet using which was
$51 \%$ as easy source of anemia information.

The rapid growth of computer based electronic communication and the shift toward giving patients more responsibility for their healthcare decisions are likely to induce cultural changes in the delivery of care. (Kassirer, 1995; Laporte et al., 1996) Until recently, it was extremely difficult for lay people to search for healthcare information on the internet, but applications such as the world wide web are making it more accessible.(Pallen, 1995; Laporte,1994; Widman and Tong,1997). This changing nature of information distribution has important implications for health care: issues such as the quality of care, the validity and consistency of available information, and the effects on the doctor-patient relationship will be major concerns. (Coeira, 1996; Silberg et al., 1997).

There was shortage in health professional role to boost the Saudi citizen conscious, the health facility environments should be ideal to address anemia causes, prevention, and 
treatment. These facilities would have to be staffed by trained health care clinicians or health educators who are qualified to provide anemia prevention and treatment education. Patient oriented medical information on the World Wide Web could provide healthcare professionals with the opportunity to learn more about patients' and relatives' concerns and to refer them to these sources of information when appropriate.( Spooner, 1996) However, little has been done to assess, control, and assure the quality of this medical information.

\section{CONCLUSION}

We conclude that general awareness of anemia is very good, but still more efforts should be performed through information sources channels to boost of anemia awareness in Saudi population in Qassim area to reach satisfactory knowledge, which reflect in life style and hygiene behavior.

\section{ACKNOWLEDGEMENT}

The authors are grateful to all students at Qassim University who participated in data collection of this study. Thanks also are due to Mr. Yousef Musaad, College of Bioinformatics for his guidance in statistical analysis.

\section{REFERENCES}

Bothwell T, Charlton R. (1981). Iron deficiency in women. Washington DC, Nutrition Foundation.

Coeira E. (1996). The internet's challenge to health care provision. BMJ; 312:3.

Fredrick M; Abrahamian, DO (2009). eMedicine-Anemia, Chronic : FACEP".Emedicine.com. Retrieved 2010-08-24.

Green, S., Higgins, J PT., Alderson, P., Clarke, M., Mulrow, CD and Oxman, AD. (2009). Cochrane handbook of systematic reviews of interventions. Julian PT Higgins and Sally Green (Editors), Cochrane Collaboration, Mary Land University press.

Kassirer J P. (1995). The next transformation in the delivery of health care. N Engl J Med, 332:52.

Laporte R E. (1994) Global public health and the information superhighway. BMJ, 308:1651.

Laporte, R. E.; Barinas, E.; Chang, Y F. and Libman, I. (1996). Global epidemiology and public health in the 21 st century. Application of new technology. Ann Epidemiol; 6:162.

Macgregor, M. (1963). Maternal anaemia as a factor in prematurity and perinatal mortality. Scottish Medical Journal., 8:134.

Pallen, M. (1995). The world wide web. BMJ; 311:1552.

Scholl, T O. and Hediger, M L. (1994). Anemia and iron-deficiency anemia: compilation of data on pregnancy outcome. American Journal of Clinical Nutrition., 59:492- 500 .

Silberg W M.; Lundberg G D. and Musacchio, R A. (1997). Assessing, controlling, and assuring the quality of medical information on the internet. JAMA, 277:1244.

Spooner, S A. (1996). The pediatric internet. Pediatrics, 98:1185.

Widman, L E. and Tong, D A. (1997). Requests for medical advice from patients and families to health care providers who publish on the world wide web. Arch Intern Med, 157:209.

World Health Organization, (2001). Iron deficiency anemia: assessment, prevention, and control. A guide for programme managers. Geneva.

World Health Organization. (2002). The World Health Report 2002: Reducing risks, promoting healthy life. Geneva. 